\title{
Students' Ideas on Cooperative Learning Method
}

\author{
Abdulkadir Yoruk \\ Department of Elementary Science Education, Faculty of Education, Siirt University, Turkey
}

Copyright $(2016$ by authors, all rights reserved. Authors agree that this article remains permanently open access under the terms of the Creative Commons Attribution License 4.0 International License

\begin{abstract}
Aim of this study is to investigate students' ideas on cooperative learning method. For that purpose students who are studying at elementary science education program are distributed into two groups through an experimental design. Factors threaten the internal validity are either eliminated or reduced to minimum value. Data analysis is done through primary document analysis. Further analyses are done to investigate gender factor in the study. Research revealed that cooperative learning method increases students' awareness to their environment and courses, self efficacy, self confidence and help students to socialize. Interesting point of the study is that image or perception of gaining information differs with respect to gender.
\end{abstract}

Keywords Cooperative Learning, Jigsaw, Students, Ideas, Teaching, Instruction

\section{Introduction}

Schools have the purpose of helping the individuals to be a person who has the power of knowledge and a social person. Thus modern methods have been introduced to educational environment for that purpose. Other aspect of those methods is that their harmony with developmental stage of the children (students) [1]. Modern methods enable the students to be active inside and outside of the classroom. For that reason teachers use those methods to help the students for their development [2]. Main advantages of those methods are;

- They don't need to be fixed with a time schedule (flexibility)

- Encourage students to think in different ways

- Process is also one of the important outcomes

- Teachers have many and different type of feedbacks

- Learning to learn is much more important than memorizing the knowledge [3]

Cooperative learning method is one of those modern methods. It aims to develop psychomotor, cognitive and affective domains of the students. Students are encouraged into self learning methods and to share the knowledge they have and help each other during the study. Being in similar age groups also is the key for understanding each other, and teachers become guide for learning rather than being facilitator [4]. Cullen [5] reports that students who study with cooperative learning models tend to be a giver and taker in the group works which also enable the teachers to have desired student models. Simsek [6] points out it as a fine method which helps the children improve their cognitive development and hence their grades. Dikel [7] in his study claims cooperative learning methods have academic, social, psychological, assessment and evaluation and economic benefits. Cooperative learning method has many techniques, and one of them is jigsaw technique. Jigsaw technique has few sub techniques and in this study Subject Jigsaw technique is used. That technique first introduced by Doymus [8].

\section{Purpose of the Study}

Purpose of this study is to investigate students' idea on Cooperative Learning Method (CLM) and its effect on cognitive and affective attributes.

\section{Methodology}

\subsection{Before Study}

This study is done through pre-test, post-test experimental design which is one of the quantitative methods. Study is carried out with students who are taking chemistry laboratory course and studying at elementary science education program at first grade at university. All the students taking the course participated in the study and total number of students is 60 . To carry out the study students are divided into two groups. Dividement is done with respect to pre-test scores of students who are taking course. Firstly students are listed in an order with respect to pre-test scores, consisting of total 60 students. Then students are distributed randomly into two groups through s distribution method. By doing this it is ensured that academic levels of students are close to each other for both experiment and control groups. 
First group is selected as control group. Laboratory activities with this group are carried out with traditional method as curriculum advised. Second column is selected as experiment (jigsaw) group. 12 boy and 18 girl, total 30 students. Laboratory activities carried out is same with control group however students' study at the laboratory is designed with respect to jigsaw method. Five experiment topics are selected to be carried out in the laboratory. Each week an experiment topic is carried out in the laboratory. For internal validity of the study same instructor worked with both control and experiment group. However to answer the purpose of the study a survey is done which has open ended questions. So main method of the data analysis is based on primary document analysis of the grounded theory which is one of the qualitative methods. Since the purpose of the study is to determine students' ideas on CLM, survey is only given to experiment group and feedback taken from all the students who worked in experiment group. Thus there is no feedback from the students who worked in control group.

\subsection{Jigsaw Appliance in the Laboratory}

Students are informed about jigsaw technique and then randomly divided into five groups. Each group consisted about four or five students. Each group is named alphabetically (Group A, Group B, Group C, Group D and Group E) and students in the groups are tagged with respect to group name. For example first student in group A is tagged as A1, and last student is tagged as A5. This step is applied for all groups. Groups are informed about that they will take two quizzes before and after the experiment.

After creating groups; each third tagged student in each group is selected as group leader who is responsible of regulating the group work. Later, students with same number created a different group which is named as specialized group. Each specialized group studied only one specific experiment. Students studied the theoretical elements of experiment and prepared questions related to the experiment, and then they passed into second phase (first week).

Second Week: students carried out experiments and outlined problems or obstacles they encountered during experiments. Those obstacles might be related with doing experiments or understanding the experiments. Studying experiment both theoretically and experimentally each student in the specialized groups are titled as teacher of the experiment, and asked to teach and carry out the experiment with their original groups next week.

Each week an experiment is carried out by the specialized student (teacher of the experiment) and specialized students prepared their groups to quizzes. For that purpose groups come together before the experiment theoretical (pre-experiment) quizzes and teacher of the group studied with whole group and prepared his/her group to the pre-experiment quizzes. After carrying out the experiment, teacher of the group prepared his/her group for the after experiment (post-experiment) quizzes. This phase is carried out with experiment group for five weeks and each week teacher of the experiment studied his/her group. By doing so each student become teacher of the experiment for one week.

After the study students are asked to answer open ended questions. Survey is given to all the students in experiment group, so all 30 students gave feedback. Due to possible conflict of interest students were asked to answer open ended questions anonymously. Only information asked from the students is to fill the paper indicating their age and gender. Questions asked are created by the researcher himself (Table $1)$.

Table 1. Survey Questions

\begin{tabular}{cc}
\hline Age: & Gender: \\
\hline Question 1: & $\begin{array}{c}\text { What was your expectation from Chemistry } \\
\text { Was your expectation met? }\end{array}$ \\
\hline Question 2: & Did you take science laboratory course before? \\
\hline Question 3: & Did you do science experiments before? How many \\
times?
\end{tabular}

Questions asked basically aims to determine five topics affecting the instruction and students' ideas/views (Table 2). Firstly, through data analysis, themes are determined and then topics fall into themes categories are determined.

Table 2. Topics and Their Explanations

\begin{tabular}{cc}
\hline Topics & Topics Explanation \\
\hline Topic 1 & Previous learning and experiences \\
\hline Topic 2 & Students' views on instruction method \\
\hline Topic 3 & Contribution of method to learning and students \\
\hline Topic 4 & Views on teacher's instructional method and attitude \\
\hline Topic 5 & Improvement in Self efficacy and Self confidence \\
\hline
\end{tabular}

\section{Data Analysis}

This study is done through unstructured survey method 
and this research is an action research. Once the survey has been conducted, analysis undertaken around themes represented in the question topics. For further investigation of data hermeneutic analysis is also done, by doing that it also aimed to put gender difference effect on the study. To reveal the data further coding is also done through empirical coding. Themes, topics and codes are placed within categories and their relations with themselves are outlined.

There are four themes determined through the analysis. Each theme is shown in Table 3.

Table 3. Themes

\begin{tabular}{cc}
\hline Theme 1 & Social relationship \\
\hline Theme 2 & Learning outcome of the course and its value \\
\hline Theme 3 & Investment in future job. Expectations \\
\hline Theme 4 & Confidence in teacher and confidence in her/himself \\
\hline
\end{tabular}

It has been revealed that topic 1 fall into theme 2 and theme3

Topic 2 fall into theme 1 and theme 4

Topic 3 falls into theme 3

Topic 4 falls into theme 2 and theme 3 , theme 4

Topic 5 falls into theme 3 and theme 4

It has been revealed by the survey that only two male students have doing experiment experience previously. First student stated that he had nearly 20 experiment sessions and second student stated that he had 5 experiment sessions during high school or elementary school. However rest of the male students did not have a laboratory course before and only had a 1 or 2 laboratory experiment at most in previous education life. That reveals also that students did not have higher order thinking experiments previously and their knowledge of experiment is basically theoretical.

It has been understood from codes and their relations with themes revealed that enjoying the course leads the students to understand better on the topics covered during experiment. This understanding is also accepted as gaining.

Here are some student statements

"It made me like the chemistry"

"I had lots of gaining from this course"

"I learned a lot of things from chemistry laboratory that I could not learn from chemistry course. It was so rational"

"Chemistry laboratory is fun"

"Sometimes our topic teacher cannot teach but we help each other and learn"

It is clear from data analysis that students share the responsibility and due to nature of cooperative learning method they tend to help each other. Another important point is that students learn the value of responsibility. This probably happens due to method's order of work.

"I do not want to work with this method again because I believe I cannot help my friends"

An interesting point is that some students stated that "students lack on information, I want to learn directly from the instructor". However it is also interesting that all of the students stated that they have learned a lot and this way they improved themselves. That is another sign of benefits of cooperative learning method (CLM). Students proceed step by step and follow a ration directed by the method. CLM increases students' awareness on subject topics and help students to bear responsibility which also drives them to realize their potential, drive them to learning and being self confident. For example one male student answered question 8 in one word as "responsibility". It is also noteworthy that CLM make students have confidence in teacher although some claim teacher to be a cold person and not having friendly relationship with them. A student stated "teacher looks like a hard person and he has harsh rules however he also values the course. That helps us a lot" while another student states "teacher is hard on us however I do like that. That way makes us to learn everything". Although it is not really apparent at first in the data a deep look on the coding and themes reveals that teacher's attitude being very careful on the course instruction method and his neutrality or equal distance to every students eventually drives the students to have confidence in teacher and his way of instructing. It is very interesting that method also makes students to have confidence in themselves. For instance a male student stated "since we do experiments by ourselves it makes us to trust in ourselves and also learning is permanent". The most interesting reveal of the data is that if there is a problem in the group working process or if students realize there will be a problem in the group working process they tend to escape from responsibility that is in fact a sign of responsibility. There were 2 students who did not want to be group leader and four of the students also did not want to establish groups by themselves instead of teacher. Some students stated that by "I will make groups with my best friends and that way we just make fun at the course hours and will not study" while others stated "I do not want to deal with that". However that does not always mean there is/will a problem in group working process. Because there are also ideas supporting the teacher in making groups by stating "teacher made groups make class to have a better friendship among the classmates".

In constructivist theory it is aimed to guide students to learning and help them in learning process. A teacher should not lecture always but instead help the students to be future lecturers of the world. Study reveals that purpose is achieved. Majority of the students claimed teacher did not help them, did not lecture to them, students' information was not enough to learn. Yet that majority also stated that they would not learn so much if there was not help of teacher. They gained so little information without help of teacher. Statements below are clear example for that idea revealed by the question 13.

"Nothing", "only \%2" and "not much".

The most important of the acquisition of the study is that it increased awareness of the students about themselves, course and their surroundings. For example some students declined 
to answer question 15 since they did not have a laboratory course before, and it would not be just to answer question. Because answering that question requires a comparison with previous experience and they did not have such experience. Although this is the case for experience, same thing did not happen for physical conditions. Almost all of the students mentioned about physical conditions of the laboratory such as "materials were not enough" or "some of the tools were broken or not working".

\subsection{Revealing for Girls}

In this part it is aimed to show similarities and differences between female and male students.

It has been revealed by the survey that only two female students did an experiment previously. There was only one student stated that she had nearly 10 experiment sessions and other students stated that they either had few experiment session ( 2 or 3 times) or no experiment sessions at all during high school or elementary school. That case is similar with male students and it also shows girls have similar conditions with males and did not have higher order thinking experiments previously and their knowledge of experiment is basically theoretical. However as a reminder it should be noted that female students responded to questions more in detail. For example word count for male students 640 and word count for female students is 1415 . That makes a first impression on that female students tend to involve in the purpose of study much more than boys.

Almost all of the female students stated that they enjoyed the course and they learned a lot.

Here are some student statements

"I hoped experiments would relate with daily life and they did"

"I knew we would deal with experiments but I did not expect to get in so much detail and knowledge in so simple experiments"

Girls tend to discuss more detail than boys and value the learning outcome of the laboratory appeared similar levels with like boys. The one thing should be mentioned is that girls also note on the process of the method

"I did not understand at first what was happening. I really had trouble with laboratory but suddenly I realized I am learning new things"

That is important because it also implies that students need time to get used to method used in the laboratory course. That case is also an expected thing since the students did not have previous laboratory experience.

"It is fun to make experiments with my friends however some of them are lazy"

"I learned chemistry better with this method"

"I found myself as a teacher"

Sharing responsibility is also similar with boys. The interesting thing happened at the answers of question 11 .
While boys try to escape from responsibilities in group making, girls on the other hand tend to be group leaders due to share responsibility. For instance one of the female students stated "I want to be group leader due to some students who are really not working". That also reveals one attitude difference between boys and girls. While male students try to avoid being group leader due to possible confrontation with other group members, female students want to engage in that possibility for the good of group work. That also explains girls' tendency being leader in groups is higher when compared to boys. This situation may also caused by dramatic increase of self confidence. For example a female student stated "I did not have self confidence in myself however by lecturing my friends now I have, I felt like a teacher"

An interesting point is on the teacher and his attitude. While male students described the teacher as harsh and strict on his rules, girls stated that teacher is cold, not interested in his students as desired. Even one student stated "he does not seem to know much". That drives the idea that female students are more into closer relationship with teacher. Their idea of teacher and learning is mostly based on the dialogue with teacher and assume indication of knowledge level is proportional with dialogue. For example respondents for the question 13 stated their knowledge without help of teacher as "\%50" and "\%85". However other respondents also reveal that purpose of constructivist theory is also achieved. Yet it also should be noted that their perception of good dialogue is mostly based on possible grading. For instance a female student described teacher as "person who really ask hard questions on experiments". This is also an indication of gender differences effect on teacher student interaction. Where male students mostly focused on learning and its outcome, female students also focus on not to involve any fallbacks such as not being able to answer the questions of teacher, and possibility of dialogue cutbacks.

"I now know research method and how to look for information"

"I learn what I have to learn however I learn details from the teacher"

"I learned that I could achieve things by myself"

Although there are some female students who state teacher as "a friendly person who increased our self-confidence in ourselves" or "I would like to work with same teacher again because he never gives us information directly but makes us to learn by ourselves" it is understood from the data analysis female students care closer relationship with teacher more than male students, and male students may look like more professional than female students. However coding and themes show both gender focuses on learning, future life expectations and are job oriented. Female criticism on teacher attitude is also due to possible learning. Girls tend to think that interaction level with teacher will increase the chance of learning. Female students' high word usage in numbers, stating teacher a key element in increase of self confidence are just clear examples of that. 


\section{Conclusions}

This study reveals there are four elements in CLM instruction and students tend to do better base on those themes. Outcome of this study reveals that although there may seem gender difference in education, in fact it is mostly regarded as social interaction and does not affect instruction.

CLM is an effective method which increases students' sociality, self confidence and awareness on the environment and courses. Another important outcome of the study is its implications on teaching to students the research methods and increase in confidence teachers' instructional method.

It is believed that implementation of CLM into classroom environment or laboratory environment will have positive outcome from the classroom environment and will help their students to be a self confident person who realizes his/her world, surroundings, and a well trained candidates in their future jobs. Increase in self efficiency will also lead students to be the persons who know themselves and their abilities and hence to an analytical thinkers in their community.

\section{REFERENCES}

[1] Nilsson P, Driel J 2010. Teaching together and learning together- Primary science student teacher's and their mentors' joint teaching and learning in the primary classroom. Teaching and Teacher Education, 26: 1309-1318.
[2] Karacop A, Doymus K 2013. Effects of Jigsaw Cooperative Learning and Animation Techniques on Students' Understanding of Chemical Bonding and Their Conceptions of the Particulate Nature of Matter. Journal of Science Education and Technology, 22: 186-203.

[3] Behzadi Z, Ghaffari A 2011. Characteristics of Online Education and Traditional Education. Life Science Journal, 8 (3): 54-58.

[4] Okebukola P.A, Owolabi O, Okebukola F.O 2013. Mother Tounge as Default Language of Instruction in Lower Primary Science Classes: Tension between Policy Prescription and Practice in Nigeria. Journal of Research in Science Teaching, 50 (1): $62-81$.

[5] Cullen D.M 2012. Model Engagement for Your Students. Journal of Chemical Education, 89: 565-566.

[6] Simsek U 2012. Effects of two cooperative learning strategies on achievement in chemistry in undergraduate classes. Energy Education Science and Technology Part B-Social and Educational Studies, 4 (2): 901-912.

[7] Dikel S 2012. Fen ve Teknoloji Öğretmenlerinin İşbirlikli Öğrenme Modeli Hakkında Bilgilendirilmesi, Bu Yöntemi Sinıfta Uygulamaları ve Elde Edilen Sonuçların Değerlendirilmesi: Erzurum İl Örneği. Master Thesis, Unpublished. Erzurum: Atatürk University.

[8] Doymus K 2007. Effects of a Cooperative Learning Strategy on Teaching and Learning Phases of Matter and One-Component Phase Diagrams, Chemical Education Research, 84 (11): 1857-1860. 